\title{
Effect of Activated Carbon Source from Date Stone on Its Physico-Chemical Properties
}

\author{
Mohamed Erhayem, Ragwan Mohamed, Osama Ghmeid, Abobaker Eljelane, and Mohammed \\ Elhmmali
}

\begin{abstract}
This work looks more specifically at the effect of agriculture material source on its physico-chemical properties. Seven date stone (DS) samples were collected from north (N-DS) and south (S-DS) of Libya. Chemical activation method was used to prepare activated carbon from DS (ACDS). The pH, conductivity and ash content varied in the order of N-ACDS>S-ACDS. The moisture content of ACDS samples were in the range of 3.89 to $10.4 \%$. The bulk densities of ACDS samples were ranged from 0.271 to $0.549 \mathrm{~g} \mathrm{~cm}^{-3}$. The $\mathrm{pH}$ of ACDS samples were slightly acidic to neutral in nature ranged from 4.51 to 7.15. The functional groups present on the surface of DS samples were similar but their intensities were different. The findings in this research suggest that the biomasses from different source influence their physical and chemical properties, which affect their applications differently.
\end{abstract}

Index Terms-Activated carbon, date stone, physical-chemical properties.

\section{INTRODUCTION}

Activated carbons are the most widely used as industrial adsorbents for removing pollutants from gaseous and aqueous Pervious studies have shown that activated carbons can be obtained from almost all carbon-rich materials, such as wood, fruit stones, peat, lignite, shells and other raw materials [1]. However, different types of activated carbon have been applied in pollution control, such as zeolites, polymers, silica gel and alumina [2]-[4]. Agriculture waste materials, which impact negatively on environment, have been commonly applied over other adsorbents due to low or zero cost materials. Also, these materials have excellent properties for removing pollutants like their high surface area, pore size distribution and functional groups on their surface.

Date plant is widely grown in global, especially in Middle East, with only $5 \%$ of total waste used to generate heat for boiler of global date production [5]. The date plant agriculture companies produce large amount of solid wastes as DS. The percentage of waste agriculture DS is about $20-40 \%$ of all date fruit. Also, these DS materials could be used as adsorbent to remove the pollutants from aqueous solutions using adsorption processes due to DS is low or almost zero cost

Manuscript received May 21, 2015; revised July 12, 2015.

Mohamed Erhayem and Mohammed Elhmmali are with the Chemistry Department at University of Sebha, Sebha, Libya (e-mail: irhim2002@yahoo.co.uk).

Ragwan Mohamed is with Chemistry Department at University Sirte, Sirte, Libya (e-mail: ragwan3000@yahoo.com).

Osama Ghmeid is with the Scientific Laboratory at University of Sebha, Sebha, Libya.

Abobaker Eljelane is with the Agriculture Department at University of Sirte, Sitre, Libya. material and its physico-chemical properties [6]. Therefore, the agro-industrial biomass residues, DS, could effectively be converted into activated carbon using chemical or physical processes.

Over past decay, the preparation of activated carbon form waste agriculture materials has been given a serious attention in many fields, like renewable biomass and treatment of drinking water [3]. To improve these material properties, chemical or physical activation processes are two main methods for preparation of activated carbon. Numerous of researches have been carried out using different raw agriculture materials interchangeably to prepare activated carbon for removing heavy metals from aqueous solutions. These studies have reported on the development of activated carbon materials from cheaper and readily available agriculture waste materials [7], [8]. The main objective of this research was to expand our understanding of the effect agriculture waste material source on its physico-chemical properties using DS samples from different sources.

\section{MeTHODOLOGY}

\section{A. Instruments}

$\mathrm{pH}$ meter (Thermo, Orion4 star); conductivity meter (Philips, PW-9527); element analyzer (EA-1112); atomic absorption spectrophotometer, Thermo AA spectrometer S-series; FT-IR spectrometer.

\section{B. Sample Collection and Preparation}

Seven DS samples were collected from two main areas: form north (N-DS) of Libya namely Zamzam (DS1), Abogren (DS2), Alwashka (DS3) and Sirte (DS4); from south (S-DS) of Libya namely Waddan (DS5), Hun (DS6) and Sokna (DS7); all originating from Libya. The DS samples were washed several times with distilled water in order to remove the dirt, dust and fine. Then, they were dried at $105^{\circ} \mathrm{C}$ for $24 \mathrm{~h}$, later grounded to obtain a powder form and sieved to a $200 \mu \mathrm{m}$.

\section{Chemical Activation and Carbonization}

$20 \mathrm{~g}$ of pre-treated samples was immersed into preheated $100 \mathrm{ml}$ of $\mathrm{HNO}_{3}\left(\% 60 ;\right.$ w/w) with ratio 1:5 (DS: $\left.\mathrm{HNO}_{3}\right)$ [9]. The suspensions were allowed to soak at $110^{\circ} \mathrm{C}$ for $3 \mathrm{~h}$ and then left to cool to room temperature for overnight. The samples were washed with distilled water until $\mathrm{pH}$ of activated carbon DS remained constant and then dried at $200^{\circ} \mathrm{C}$ for $3 \mathrm{~h}$. Finally, the DS samples were crushed and sieved to a particle size with a $500 \mu \mathrm{m}$ sieve, and stored in desiccator in tight container till its use. 


\section{Characterization of Activated Carbon}

Carbon Yield. The DS sample was dried at $105^{\circ} \mathrm{C}$ for $1 \mathrm{~h}$ and weighed using KERN ALS120-4 balance. The percentage carbon yield was calculated by the following equation:

$$
C Y \%=\frac{W_{1}}{W_{2}} \times 100
$$

where $C Y \%=$ percentage carbon yield $(\mathrm{g}) ; W_{1}=$ weight of ACDS $(\mathrm{g})$ and $W_{2}=$ dried weight of raw DS prepared.

Determination of $\mathrm{pH}$ and Conductivity of Carbon Solution $1.0 \mathrm{~g}$ of DS was weighed and mixed with $100 \mathrm{ml}$ distilled water. The mixture was stirred for $60 \mathrm{~min}$ to ensure proper dilution of the sample and filtered out. The $\mathrm{pH}$ and conductivity of filtered solution were determined by digital $\mathrm{pH}$ and conductivity meter.

Determination of Moisture Content (MC). ASTM method D280-33 was used to determine the hydroscopic moisture without any modifications. $0.5 \mathrm{~g}$ of $\mathrm{DS}\left(W_{i}\right)$ was weighed and dried at $105^{\circ} \mathrm{C}$ for $60 \mathrm{~min}$. The sample was constantly reweighed every 10 min until a constant weight $\left(W_{f}\right)$ and cooled in desiccator. The percentage moisture content (MC\%) was calculated by the following equation:

$$
M C \%=\frac{W_{f}-W_{i}}{W_{f}} \times 100
$$

Determination of Ash Content (AC). ASTM method D2866-94 was used to determine the ash content of DS. Dry DS sample $\left(0.5 \mathrm{~g} ; W_{i}\right)$ was placed into porcelain crucible and transferred into preheated muffle furnace set at $1000^{\circ} \mathrm{C}$ for $3 \mathrm{~h}$ The crucible was transferred to desiccator, allowed to cool for $3 \mathrm{~h}$, and then reweighed $\left(W_{f}\right)$. The percentage ash content $(\mathrm{AC} \%)$ was calculated by the following equation:

$$
A C \%=\frac{W_{f}}{W_{i}} \times 100
$$

Pore Volume $(P V)$ Measurement. Total volume was determined by transferring $1.0 \mathrm{~g}$ of DS into measuring cylinder. Then, the sample was immersed in $20 \mathrm{ml}$ water and boiled for $15 \mathrm{~min}$ in order to displace air from the pores. The mixture was filtered out, superficially dried and weighed. In order to determine the pore volume of DS sample, the increase in weight of sample was divided by the density of the sample.

Determination of Bulk Density (BD). The sample of DS was placed into a cylinder with volume known and reweighed. The $B D$ was calculated by the following equation:

$$
B D=\frac{W_{D S}}{V}
$$

FT-IR and Metal Analyses. A few milligrams of each the DS was placed on FT-IR lense. The wave number was ranging from 400 to $4000 \mathrm{~cm}^{-1}$. Carbon, nitrogen, hydrogen and sulfur were measured using elemental analyzer (EA-1112). EPA method 3050B, acid extraction method, was followed to determine metal concentrations using AAS. $0.5 \mathrm{~g}$ of dried DS sample was digested in $5 \mathrm{ml}$ of $\mathrm{HNO}_{3}$ and $2 \mathrm{ml}$ of $\mathrm{HCl}$ for 15 min. The sample was allowed to cool and then diluted to $25 \mathrm{ml}$ with distilled water.

\section{E. Statistical Analysis}

Experimental data was statistically analyzed using Microsoft Office Excel 2007 and ANOVA at 0.05 level of significance.

\section{RESUlTS AND DiscUSSION}

\section{A. Proximate Analysis Results}

Table I shows the list of ACDS from different source and their characteristics. The acidity or basicity of activated carbon depend on its preparation, inorganic matter and chemical active oxygen groups on the carbon surface. The $\mathrm{pH}$ of N-DS solution was generally natural (7.0) except DS4 (4.8), while the $\mathrm{pH}$ of S-DS solution was generally acidic (4.7). The acidic $\mathrm{pH}$ of DS solution could be due to related to the source of DS. The natural $\mathrm{pH}$ of N-DS solution could be due to the collection place of DS was near to sea. On the other hand, the high $\mathrm{pH}$ of DS indicated much contamination. However, the useful $\mathrm{pH}$ for most applications of activated carbons is between 6 to 8 , while the distinctly acidic of activated carbons is not desirable [10]. It should be noted that carbons of acidic $\mathrm{pH}$ are desirable for adsorption applications. It was found that the suspension $\mathrm{pH}$ affects the rate of activated carbon adsorption, which is more effective at low $\mathrm{pH}$ than high $\mathrm{pH}$ [3]. The value of $\mathrm{pH}$ found in this work could be acceptable for most application such as adsorption of heavy metals from aqueous solutions, especially for S-DS samples. The water soluble minerals were studied using conductivity, which showed similar trends as $\mathrm{pH}$. The conductivities of N-DS samples were generally higher than those of S-DS samples.

\begin{tabular}{|c|c|c|c|c|c|c|c|}
\hline Properties & DS1 & $\mathrm{DS} 2$ & DS3 & DS4 & DS5 & DS6 & DS7 \\
\hline C Y\% & 24.5 & 27.3 & 21.2 & 38.0 & 28.4 & 20.8 & 25.3 \\
\hline $\mathrm{pH}$ & 7.15 & 6.98 & 6.96 & 4.80 & 5.04 & 4.51 & 4.75 \\
\hline \multicolumn{8}{|l|}{ Conductivit } \\
\hline $\begin{array}{l}y \\
(\mu \mathrm{S} / \mathrm{cm})\end{array}$ & 411 & 415 & 412 & 285 & 224 & 292 & 209 \\
\hline TDS (mg/L) & 243 & 249 & 247 & 171 & 134 & 175 & 125 \\
\hline Solubility\% & 9.32 & 9.42 & 9.13 & 9.47 & 9.66 & 9.48 & 9.58 \\
\hline $\mathrm{MC} \%$ & 9.03 & 7.19 & 4.32 & 7.28 & 8.94 & 3.89 & 10.4 \\
\hline $\mathrm{AC} \%$ & 3.65 & 3.31 & 3.38 & 1.91 & 1.05 & $\begin{array}{l}0.85 \\
6\end{array}$ & 1.03 \\
\hline \multirow{2}{*}{$\mathrm{PV}\left(\mathrm{cm}^{3} / \mathrm{g}\right)$} & 0.01 & 0.03 & 0.06 & 0.04 & 0.00 & 0.02 & 0.01 \\
\hline & 4 & 8 & 2 & 1 & 7 & 1 & 5 \\
\hline \multirow{2}{*}{$\mathrm{BD}\left(\mathrm{g} / \mathrm{cm}^{3}\right)$} & 0.54 & 0.45 & 0.47 & 0.34 & 0.27 & 0.35 & 0.28 \\
\hline & 9 & 3 & 2 & 5 & 1 & 8 & 9 \\
\hline
\end{tabular}
This was probably due to the source of DS samples.

TABLE I: PHYSICO-CHEMICAL CHARACTERISTICS OF ACDS SAMPLES USING PROXIMATE METHODS

In comparison to other studies, the high conductivities of DS samples related to that the acid or water wash may not have been able to reduce leachable ash level observed in commercial carbons ranges from 52 to $71 \mu \mathrm{S} / \mathrm{cm}$ [10]. This could be also related to the presence of substantial amounts of water soluble minerals remained in the DS samples. However, 
the ash content is used as an indicator of the activated carbon quality and is not desirable for decolonization and adsorption applications. It found that the ash content was not high for all DS samples studied with similar trends as $\mathrm{pH}$, conductivity and salinity [10]. Therefore, the conductivity values and ash contents found to be acceptable for most application such as adsorption of heavy metals from aqueous solutions, especially S-DS samples.

The Bulk density is dependent on organic matter, texture and packing arrangement. It was found that the bulk density of N-DS samples was higher than those of S-DS. Generally, well aggregated, porous materials and rich in organic matter have lower bulk density. However, bulk density is important because the higher bulk density is better the filterability of activated carbon. Also, the bulk density of DS was in the range of $0.271-0.549 \mathrm{~g} / \mathrm{cm}^{3}$, which generally higher than lower limit of $0.25 \mathrm{~g} / \mathrm{cm}^{3}$ for granular activated carbon. Therefore, DS samples were to be acceptable for most application such as adsorption of heavy metals from aqueous solutions. This result is in good agreement with previous research [11].

The carbon yield is the original precursor amount remaining after activation process. It has been reported that the carbon yield is dependent on activation conditions used. In this study, the activation process was kept the same as described in experimental section while the source of DS was changed. The carbon yield for N-DS ranged from 23 to $38 \%$ while S-DS showed a range of 20 to $28 \%$. Even though, the difference between DS carbon yields was not in order, but the effect of DS source can be considerable between DS samples. Moisture content is an important factor for the selection of energy conversion process technology which requires low moisture content of less than $15 \%$ [12]. Generally, the percentage of moisture content of activated carbon should be more than $15 \%$ to be considered low moisture content. On the other hand, the moisture content does not affect the adsorptive power of activated carbon. The moisture content tended to be low for all DS samples used in this study indicating that these DS samples were properly prepared and handled well [3], [13]. It should be noted that the percentage of DS moisture content was ranged from 3 to $11 \%$. This may be related to the source of DS. Pore volume was also studied for DS samples, shown in Table I. It was noticed that the pore volumes of DS samples were increased in order, DS1 > DS2 > DS3 > DS4 > DS6 > DS7 > DS5. The pore volumes of N-DS samples were relatively higher than those of S-DS samples. Large pore volumes of $\mathrm{N}$-DS samples are advantageous in removing larger molecules from aqueous solutions; therefore, N-DS samples could be applied as adsorbents more than S-DS. Therefore, at the same physico-chemical conditions, the range of changes in physico-chemical properties of ACDS depended on the source of DS raw materials used.

\section{B. Ultimate Analysis Results}

Fig. 1 shows the results of element analysis present in DS samples suing element analyzer (EA-1112); N/C, O/C, S/C and $\mathrm{H} / \mathrm{C}$ ratios were also studied using the following equation:

$$
\frac{Y}{C}=\frac{\% Y / M_{m(y)}}{\% C / M_{m(c)}}
$$

where $Y / C$ is atomic ratio for the element $Y(\mathrm{H}, \mathrm{O}, \mathrm{N}$ and $\mathrm{S}) ; \%$
$Y$ and \% $C$ are the mass percentages of element $Y$ and carbon. $M_{m(y)}$ and $M_{m(c)}$ are the molar masses for element $Y$ and carbon [10], [13].

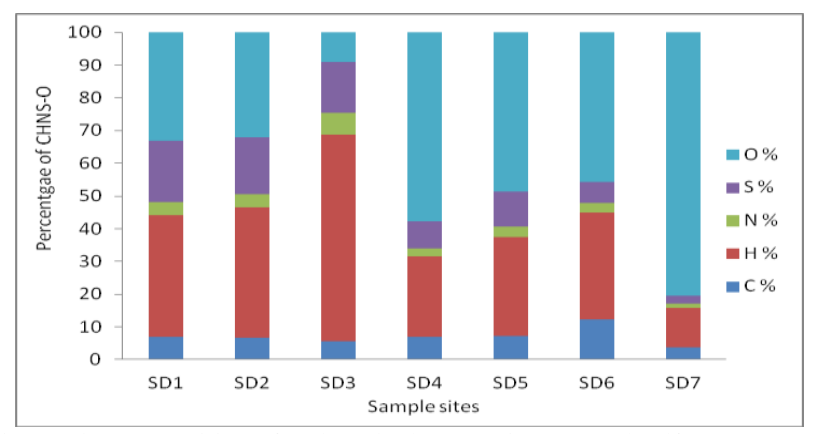

Fig. 1. The composition of carbon, hydrogen, nitrogen and sulfur (CHNS-O) in DS samples.

It was noted that the DS samples were contained high percentage of $\mathrm{H}$ and $\mathrm{O}$. on the other hand, the amount of $\mathrm{C}$ presence in DS samples was low. This may be due to the carbonization process was at slightly low temperature $\left(200^{\circ} \mathrm{C}\right)$. The trend of percent $\mathrm{C}$ was: S-DS $>\mathrm{N}-\mathrm{DS}$ samples with exception of DS7. The N-DS samples contained slightly higher level of sulfur than S-DS. This may be due to these DS were collected from place closed to spring waters which conation high level of sulfur. The $\mathrm{H} / \mathrm{C}$ ratios were slightly high which might be due to cyclization process was predominant during carbonization process at low temperature used. The trends of $\mathrm{O} / \mathrm{H}$ ratios were: $\mathrm{S}-\mathrm{DS}>\mathrm{N}-\mathrm{DS}$ which might be related to the percentage of moisture content in S-DS was higher than N-DS samples. The trends of N/C ratios were: $\mathrm{N}-\mathrm{DS}>\mathrm{S}-\mathrm{DS}$ which might be related to the stabilization of nitrogen functionalities during carbonization process in N-DS was better than S-DS samples. Also, this may be due to raw DS samples were chemically activated by nitric acid leading to increase the amount of nitrogen on the surface of samples. Therefore, these ratios can be helpful to identify the origin of organic matter in sediment and, in this study, can also be used to distinguish between the sources.

\section{Element Analysis Results}

TABLE II: METAL CONTENT OF THE DS SAMPLES

\begin{tabular}{llllllll}
\hline Metals & DS1 & DS2 & DS3 & DS4 & DS5 & DS6 & DS7 \\
\hline $\mathrm{Fe}$ & 1.22 & 1.42 & 39.6 & 32.4 & 6.65 & 0.588 & 5.19 \\
$\mathrm{Ni}$ & 0.013 & 2.76 & $\mathrm{ND}$ & $\mathrm{ND}$ & 1.66 & $\mathrm{ND}$ & $\mathrm{ND}$ \\
$\mathrm{Zn}$ & 0.212 & 2.13 & 0.471 & 2.07 & 1.35 & 1.65 & 0.141 \\
$\mathrm{~K}$ & 25.3 & 192 & 193 & 78.4 & 115 & 113 & 128 \\
$\mathrm{Na}$ & 78.1 & 78.1 & 102 & 101 & 14.7 & 16.4 & 13.5 \\
$\mathrm{Mg}$ & 13.1 & 11.4 & 19.9 & 19.5 & 4.72 & 4.34 & 3.95 \\
\hline
\end{tabular}

The metals present in the DS samples including iron, magnesium, nickel, zinc and lead are listed in Table II. In order to use the DS sample in any thermo-chemical conversion process, ash forming metals are important to determine due to high contents of alkali leading to critical technical problems [10]. It can be seen from Table II that the concentration of these metals was lower than previous study; thus the DS samples used in this study can be used in removing these toxic metals from waste waters and in thermo-chemical conversion process [3]. Also, the N-DS samples display higher concentrations than S-DS samples. 
Therefore, the present of these metals depends mainly on the source material.

Surface chemistry results. Seven FT-IR spectra obtained for the chemically prepared activated carbon of DS samples were reported. These spectra were interpreted as the following major functional groups: $\mathrm{C}=\mathrm{O}\left(\sim 1680 \mathrm{~cm}^{-1}\right)$, $-\mathrm{COOH}\left(\sim 3300-2500,1110 \mathrm{~cm}^{-1}\right), \mathrm{C}-\mathrm{N}\left(\sim 1230 \mathrm{~cm}^{-1}\right)$ and $\mathrm{C}=\mathrm{C}\left(\sim 1660 \mathrm{~cm}^{-1}\right)$. Also, $\mathrm{OH}$ and $\mathrm{NH}$ groups were only presented in N-DS. Generally, similar functional groups on the DS surfaces were identified at almost similar wavelengths, but the intensities of these functional groups were different. Therefore, the percentage of functional groups present on the surface of DS samples is dependent on the source of samples.

\section{Statistical Analysis of Variance Using ANOVA}

Table III shows the values of sum squares (SS) and mean of square (MS) are 6.58E5 and 4.11E4, respectively, along rows which are higher than those along the column $(2.82 \mathrm{E} 3$ and 4.70E2). This suggests that the physico-chemical data can be compared along the rows than along the columns due to MS along to rows is greater than this of along to column. The value of $F_{\text {calculate }}$ is 76.3 while that of $F_{\text {critical }}$ is 1.75 along the rows and the value of $F_{\text {calculate }}$ is 0.873 while that of $F_{\text {critical }}$ is 2.19 along the columns. The results indicate that the values along on both rows and columns, $F_{\text {calculate }}$ is greater than $F_{\text {critical }}$ and the lower p-values in rows $(<0.05)$ indicate that the null hypothesis is rejected, hence the alternative is accepted. Therefore, a large difference exists between the adsorption data reported.

TABLE III. TOW WAY ANALYSIS OF VARIANCE OF DS PHYSICO-CHEMICAL DATA USING ANOVA ANALYSIS

ANOVA

\begin{tabular}{lllllll}
\hline $\begin{array}{l}\text { Source of } \\
\text { Variation }\end{array}$ & SS & Df & MS & F & P-value & F crit \\
\hline Rows & $6.58 \mathrm{E} 5$ & 16 & $4.11 \mathrm{E} 4$ & 76.3 & $3.21 \mathrm{E}-47$ & 1.75 \\
Columns & $2.82 \mathrm{E} 3$ & 6 & $4.70 \mathrm{E} 2$ & 0.873 & 0.518 & 2.19 \\
Error & $5.17 \mathrm{E} 4$ & 96 & $5.39 \mathrm{E} 2$ & & & \\
Total & $7.12 \mathrm{E} 5$ & 118 & & & & \\
\hline
\end{tabular}

\section{CONCLUSIONS}

In this study, the proximate, ultimate and elemental analyses of date stone samples are reported in order to study the effect of biomass source on its physical and chemical characteristics. The experimental results show much lesser values of bulk density, nutrients and heavy metals than those reported in the literature. The content of ash forming elements showed that the toxic metals were not detected in DS samples; the DS samples can be used in removing these toxic metals from waste waters. The present study revealed that the variation of physical and chemical properties was found to be depending on the sample collection site. Therefore, the use of the same biomass from different source in any applications will yield different results.

\section{ACKNOWLEDGMENTS}

The authors thank Dr. Mohamed Younis and the technicians in Research laboratory at University of Sabha for providing assistance in sample testing.

\section{REFERENCES}

[1] J. T. Nwabanne and P. K. Igbokwe, "Comparative study of lead (II) removal from aqueous solution using different adsorbents," International Journal of Engineering Research and Application, vol. 2, no 4, pp. 1830-1838, 2012.

[2] N. Boldizsar, M. Andrada, I. Cerasella, and B. L. Silvia, "Cadmium (II) ions removal from aqueous solutions using romanian untreated fir tree sawdust a green biosorbent," Acta Chim. Slov, vol. 60, no 2, pp. 263-273, 2013.

[3] B. O. Evbuomwan, A. M. Agbede, and M. M.Atuka, "A comparative study of the physico-chemical properties of activated carbon from oil palm waste (Kernel shell and fibre)," International Journal of Science and Engineering Investigations, vol. 2, no 19, pp. 75-79, 2013.

[4] K. R. Hema and A. V. S. Swamy, "Investigation on the adsorption of hexavalent chromium from the aqueous solutions using powder of papaya seeds as a sorbent," International Journal of Environmental Sciences and Research, vol. 2, no 1, pp. 119-125, 2012.

[5] C. Chakrapanic, S. Babu, K. Vani, and S. Rao, "Adsorption kinetics for the removal of fluoride from aqueous solution by activated carbon adsorbents derived from the peels of selected citrus fruits," E-Journal of Chemistry, vol. 7, no. S1, pp. 419-427, 2010.

[6] M. Singanana and E. Peters, "Removal of toxic heavy metals from synthetic wastewater using a novel biocarbon technology," Journal of Environmental Chemical Engineering, vol. 1, no. 4, pp. 884-890, 2013.

[7] P. L. Madu and L. Lajide, "Physicochemical characteristics of activated charcoal derived from melon seed husk," Journal of Chemical and Pharmaceutical Research, vol. 5, no 5, pp. 94-98, 2013.

[8] A. W. Verla, M. H. Horsfall, and A. I. S. Verla, "Preparation and characterization of activated carbon from fluted pumpkin (Telfairia occidentalis hook.F) seed shell," Asian Journal of Natural \& Applied Science, vol. 1, no. 3, 39-50, 2012.

[9] K. Qureshi, I. Bhatti, R. Kazi, and A. Ansari, "Physical and chemical analysis of activated carbon prepared from sugarcane bagasse and use for sugar decolorisation," International Journal of Chemical and Biomolecular Engineering, vol. 1, no 3, pp. 145-149, 2008.

[10] S. Garivait, U. Chaiyo, S. Patumsawad, and J. Deakhuntod, "Physical and chemical properties of thai biomass fuels from agricultural residues," in Proc. the 2nd Joint International Conference on "Sustainable Energy and Environment, 2006, C-048.

[11] M. Erhayem and M. Sohn, "Effect of humic acid source on humic acid adsorption onto titanium dioxide nanoparticles," Science of the Total Environment, vol. 470-471, pp. 92-98, 2014.

[12] A. W. Verla, M. H. N. Horsfall, and A. I. S. Verla, "Some aspects of surface chemistry of activated carbon prepared from fluted pumpkin (Telfairia occidentalis Hook.F) mesocrp by physical activation," International Journal of Chemical Science and Technology, vol. 2, no. 3, pp. 224-230, 2012.

[13] J. A. Abudaia, M. O. Sulyman, K. Y. Elazaby, and S. M. Ben-Ali, "Adsorption of $\mathrm{Pb}$ (II) and $\mathrm{Cu}$ (II) from aqueous solution onto activated carbon prepared from dates stones," International Journal of Environmental Science and Development, vol. 4, no 2, pp. 191-195, 2013.

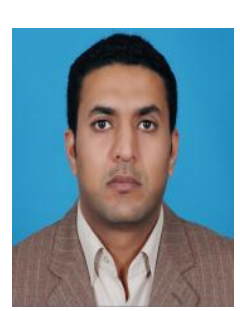

Mohamed Erhayem was born in 1973. He graduated in chemistry in 1996 and obtained his M.Sc degree in organic chemistry in 2006 from Sirte University. He completed his Ph.D in analytical chemistry (nanoparticle science) from Florida Institute of Technology, USA, in 2013.

He was working as a lecturer at University of Sirte and is currently working as a lecturer at Chemistry Department, Sebha University. Also, he is currently the vice dean of Faculty of Science at Sebha University. He has published over 8 articles in international journals and has presented several research papers at various international conferences. His research interests include nanoparticles, adsorption, kinetics, thermodynamics, agricultural waste materials, heavy metals and others.

Dr. Erhayem is a member of American Chemical Society (ACS) since 2011 under ID 30154329 and a member of Asia-Pacific Chemical, Biological \& Environmental Engineering Society (APCBEES) since 2014 under ID 100996. 
